\title{
The clinical implications of pre-liver transplant diabetes on post-liver transplant outcomes in patients with NASH: analysis of the UNOS database
}

David Uihwan Uihwan Lee ( $\sim$ dvleeman@gmail.com )

University of Maryland Medical Center https://orcid.org/0000-0001-7129-7532

John Han

Tufts University School of Medicine

Ki Jung Lee

Tufts University School of Medicine

Jean Kwon

Tufts University School of Medicine

Gregory Hongyuan Fan

Tufts University School of Medicine

\section{Daniel Jung}

UMKC School of Medicine: University of Missouri Kansas City School of Medicine

Nathalie Helen Urrunaga

University of Maryland Medical Center

\section{Research Article}

Keywords: pre-LT diabetes, liver transplant prognosis, metabolic risk factors, STAR-UNOS registry, specificcauses of death

Posted Date: February 8th, 2022

DOI: https://doi.org/10.21203/rs.3.rs-1293005/v1

License: (c) (1) This work is licensed under a Creative Commons Attribution 4.0 International License.

Read Full License 


\section{Abstract}

Background \& Aims: The presence of perioperative diabetes may lead to increased mortality risks following liver transplant (LT) in patients with non-alcoholic steatohepatitis (NASH). This risk factor was evaluated using a UNOS-STAR national database.

Methods: The UNOS-STAR liver transplant registry 2005-2019 was used to select patients with NASH (including cryptogenic liver disease). The following populations were excluded: those younger than 18 years old and those with living donors/dual transplants. Selected patients were stratified into those with and without pre-LT diabetes and compared to the individual mortality endpoints using iterative Cox analyses.

Results: 6324 recipients with and 8251 without diabetes were selected. The median follow-up time was 3.07 years. Those with diabetes were older (58.50 vs. 54.50 years, $p<0.001)$, were more likely to be Hispanic or Asian, and had higher BMI than the non-diabetics (31.10 vs. $29.70 \mathrm{~kg} / \mathrm{m}^{2} \mathrm{p}<0.001$ ); however, there was no difference in gender (female 41.9 vs. $43.1 \% p=0.170$ ). Compared to non-diabetics, recipients with diabetes had a higher rate of all-cause mortality (61.68 vs. 47.80 per 1000 person-years). In multivariate iterations, pre-LT diabetes was associated with all-cause mortality (aHR 1.19 95\% Cl 1.111.27) as well as deaths due to cardiac ( $p=0.014$ aHR $1.2495 \%$ Cl 1.04-1.46) and renal causes $(p=0.039$ aHR 1.38 95\% Cl 1.02-1.87).

Conclusion: The presence of pre-LT diabetes is associated with all-cause mortality and deaths due to cardiac and renal causes following LT. The findings warrant an early preoperative screening procedure to ensure that patients with diabetes have their metabolic risk factors optimized prior to LT.

\section{Introduction}

Currently, there is a growing incidence of NASH due to the concurrent rise in obesity and metabolic syndromes (1-3). In particular, insulin resistance and diabetes have been mechanistically linked to the growth of NASH in the United States $(4,5)$. From a physiologic level, the development of NASH is spurred by hormonal disruptions and metabolic irregularities in the liver that are caused by the desensitization of hepatic insulin receptors and insulin-mediated pathways (6), which result in dysregulated lipogenesis and steatotic changes $(7,8)$. Once steatosis and hepatic inflammation occur, fibrosis can ensue and culminate in liver failure and end-stage liver disease $(9,10)$.

For patients with NASH liver failure and hepatic decompensation $(11,12)$, liver transplant can provide curative therapy by replacing the diseased liver (13). This operative maneuver effectively normalizes the hepatic and extrahepatic manifestations of portal hypertension and liver failure and consequently improve patient survival $(14,15)$. However, with the high prevalence of diabetes found in these patients, it is important to consider the short and long-term effects of diabetes on post-LT patient survival and surgical complication risks (16). While the prognostic link between pre-LT diabetes and mortality risks has been ascertained from prior studies $(17,18)$, the connection between pre-LT diabetes and post-LT 
cardiovascular outcomes is less known (19). This is critical to evaluate, given that the association of diabetes with a significantly elevated risk of developing myocardial infarction and other adverse cardiovascular outcomes is well established in non-transplant literature (20-22). Given these observations, it is plausible that a similar mechanistic relationship can be present in patients who undergo LT, with the preoperative presence of diabetes mediating post-LT cardiovascular outcomes.

Therefore, in this study, we used the UNOS US-transplant database to evaluate the clinical implications of recipient diabetes on post-LT outcomes, specifically evaluating mortality due to cardiovascular causes.

\section{Methods}

\section{Database}

The UNOS STAR database is a compilation of patient data aggregated from the UNOS data. This data connects cases to patient outcomes and other longitudinal follow-up information. This study utilizes the UNOS STAR database and patient access files for analysis. The database contains health information gathered from the UNOS registry from 2005 to June 2019. It is rigorously maintained in confidentiality and de-identification status through safety mechanisms, shared DUA-agreements, and the Health Resources and Services Administration Contract 234-2005-370011C. The content of this study is the responsibility of the authors alone and does not necessarily reflect the view or policies of the Department of Health and Human services, nor does the mention of trade names, commercial products, or organization imply endorsement by the US Government.

\section{Study population and covariates}

This study used a stepwise and iterative approach to select patients from a predetermined raw sum, isolating the discrete NASH population without significant confounders or comorbidities. First, we selected 99987 from the database of patients who underwent LT from 2005 to 2019 . Within those selected, we excluded entries including loss of follow-up or retransplant $(n=3445)$. Then, non-complete cases without primary endpoints $(n=133496)$, those with improbable values (ie creatinine $<0)(n=15)$, and those under 18 years of age $(n=5)$ were removed $(23,24)$. Additional non-applicable setups were eliminated, which included those with living donor $(n=3116)$; non-heart beating donors $(n=4500)$; nonwhole liver transplants $(n=4026)$; hepatocellular carcinoma $(n=19029)$; other organ-dual transplants $(n=7548)$. The final remaining cohort included 14575 patients. The covariates included baseline demographics, etiologic causes (liver diseases), medication, biomarkers, liver and life-support devices (utilization - as binary marker), and donor variables. The selection of patients is delineated in Figure 1 of the study.

\section{Outcomes}

Primary and secondary outcomes included the following: death with a functioning graft, all-cause mortality (with and without a functioning graft), and graft loss following liver transplant. All endpoint 
markers were derived from UNOS, including the outcome variables as well as the censoring (negative) events.

\section{Statistical methods}

The baseline characteristics were summarized using either mean-based or nominal-based statistics, which included Fisher's or Chi-square comparison. The non-nominal variables were evaluated for kurtosis and skewness/parametricity and were further analyzed using either parametric or non-parametric testing with the Whitney $\mathrm{U}$ test. Iterative models were built using the comorbidity set into several sequential iterations (a variant of forward selection method), from which multivariate cox regression was performed using predefined outcome variables as the regression endpoints or dependent variables. The iterations included the following models: model 1 - unadjusted; model 2 - adjusted with inclusion of age, gender, race, and BMI, model 3 - additional inclusion of comorbidities, functional status, live etiologies, and medications data (both induction and maintenance data), model 4 - additional inclusion of with biomarker data, and model 5 - additional inclusion of donor information. Standard $95 \% \mathrm{Cl}$ two-tail confidence intervals with p-values of 0.05 were used to indicate statistical significance. For the all-cause mortality endpoint, Kaplan-Meier survival and hazard-event analyses were performed to derive the logrank statistics, using the prespecified strata to evaluate the comparative outcomes.

As for the competing risk analysis (graft failure versus mortality), competing risk regression using the proportional sub-distribution hazards model, delineated in the cumulative incidence function by Fine and Gray (25), was used to expose the regression representations for each hazard. This was also iterated using the sequential iterative modeling mentioned above, spanning from the unadjusted model to model 5. Interactions were evaluated using interaction plots prior to regression analyses. Aside from exclusionary variables (i.e. endpoints), variable terms were graphically analyzed to assess missingness patterns, and consequently underwent multiple imputation procedures via multiple imputation using chained equations (MICE) method to improve the statistical power and viability (26).

All tests were conducted using RStudio version 1.2.5042 with R code version 3.6.3.

\section{Results}

\section{Baseline characteristics}

After excluding patients who did not meet the eligibility criteria, there were a total of 14575 patients who were included, of which there were 6324 with diabetes and 8251 without diabetes. The median time period for follow-up was 3.07 (25-75\% IQR: 1-7.05) years, with the median time for diabetic recipients being 3.01 (25-75\% IQR: 0.99-6.91) years and the median time for non-diabetic recipients being 3.27 (2575\% IQR: 1.02-7.45) years.

The recipients with prior history of diabetes were older ( $58.80 \pm 8.31$ vs. $54.50 \pm 11.10$ years, $p<0.001)$ and were more likely to be Hispanic or Asian compared to other racial/ethnic groups (White: 77.90 vs. 
$78.60 \%$; Black: 3.62 vs. $5.16 \%$; Hispanic: 14.70 vs. $12.80 \%$; Asian: 2.36 vs. $2.17 \%$; other 1.44 vs. $1.31 \%$, $\mathrm{p}<0.001)$. Furthermore, recipients with diabetes exhibited higher BMI than the non-diabetics $(31.10 \pm 5.99$ vs. $\left.29.70 \pm 6.39 \mathrm{~kg} / \mathrm{m}^{2}, \mathrm{p}<0.001\right)$. Lastly, there was no difference in the gender distributions of the two groups (58.10 vs. $56.90 \%, p=0.170)$.

In terms of additional liver diseases, recipients with diabetes were more likely to have a concurrent diagnosis of hepatitis B (4.06 vs. $5.47 \%, p<0.001)$ as well as alcoholic liver disease $(27.00$ vs. $33.90 \%$, $\mathrm{p}<0.001)$ than those without diabetes. All patients in both the study and control groups had cirrhosis as an underlying etiology. In terms of other liver-related variables, recipients with diabetes were more likely to have undergone pre-LT TIPS (14.20 vs $9.73 \%, \mathrm{p}<0.001)$, but had lower MELD scores $(22.90 \pm 8.84$ vs $24.90 \pm 8.96, p<0.001)$ than the non-diabetics. There were no differences in the severity of ascites (absent: 14.00 vs. $13.80 \%$; slight: 47.20 vs $47.80 \%$; moderate: 38.00 vs $38.30 \% ; p=0.750$ ) and encephalopathy (none: 24.50 vs. $25.30 \%$; $1-2$ : 62.20 vs. $61.20 \%$; $3-4$ : 13.30 vs. $13.50 \%$; $p=0.400$ ) between the groups. Immunosuppressant use was also not different, with diabetics and nondiabetics utilizing the following medications: mycophenolate mofetil (MMF) ( 82.00 vs. $81.50 \%, p=0.460)$; cyclosporine (5.30 vs. $4.79 \%, p=0.170)$; tacrolimus ( 90.00 vs. $90.60 \%, p=0.200$ ); sirolimus ( 2.02 vs. $1.62, p=0.082)$; and steroids ( 90.70 vs. $91.20 \%, p=0.370)$.

When evaluating the biomarkers, the diabetic recipients, compared to non-diabetics, had higher levels of albumin ( $3.07 \pm 0.71$ vs. $3.03 \pm 0.73 \mathrm{mg} / \mathrm{dL}, \mathrm{p}<0.001)$ and creatinine $(1.65 \pm 1.13$ vs. $1.54 \pm 1.09 \mathrm{mg} / \mathrm{dL}$, p < 0.001), but lower INR ( $1.93 \pm 0.86$ vs. $2.18 \pm 1.21, p<0.001)$ and total bilirubin ( $8.30 \pm 10.50$ vs. $10.90 \pm$ $11.30, p<0.001)$. Considering donor demographics, the diabetic recipients were more likely to receive grafts from donors who were older ( $44.20 \pm 17.30$ vs. $42.80 \pm 16.90$ years, $p<0.001)$ with higher BMI $(28.30 \pm 6.88$ vs. $28.00 \pm 6.56 \mathrm{~kg} / \mathrm{m} 2, \mathrm{p}=0.037)$; however, there were no differences in donor gender ( 59.30 vs. $58.90 \%, p=0.630$ ) or race (White: 65.40 vs. $65.40 \%$; Black: 18.90 vs. $18.50 \%$; Hispanic: 11.20 vs. $12.00 \%$; Asian: 2.26 vs. $2.33 \%$; other 2.18 vs. $1.78 \%$; $p=0.230$ ).

\section{Clinical outcomes}

When evaluating the primary endpoints, recipients with diabetes had a higher incidence rate of all-cause mortality (61.68 per 1000 person-years, 95\% Cl 58.81-64.65) than those without diabetes (47.80 per 1000 person-years, $95 \% \mathrm{Cl} 45.67-50)$; likewise, when determining the crude case incidence rates, those with diabetes had a higher incidence rate of graft failure (9.52 per 1000 person-years, $95 \% \mathrm{Cl} 8.38-10.76$ ) than those without diabetes (8.76 per 1000 person-years, 95\% Cl 7.84-9.75). Upon using the iterative cox regression analysis with an escalating number of variable terms in each model, the final models for the primary endpoints demonstrated following prognostic relationships with recipient diabetes: all-cause mortality (FM [final model]: $p<0.001$, aHR 1.19 95\% Cl 1.11-1.27) and graft failure (FM: $p=0.306$, aHR 1.10 $95 \% \mathrm{Cl}$ 0.92-1.30). In the final model, both the recipient and donor variables were included in order to adjust for confounders, and the variables included demographics, etiologies and comorbidities, medications, biomarkers, and donor information as part of the model multivariate term. Figure 2 demonstrates the cumulative hazard curves for those with pre-LT diabetes compared to those without diabetes using all-cause mortality and graft failure as the primary endpoint. These curves show that 
those with pre-LT diabetes are at a higher cumulative risk for all-cause mortality throughout the follow-up time period. In contrast, the overlap between the curves for graft failure demonstrates a non-elevation in the cumulative risks between the groups. The Supplementary Figures 1 and 2 demonstrates the summarized multivariate forest plot using the pre-LT diabetes as risk variable and either all-cause mortality or graft failure as the primary endpoint.

When evaluating secondary outcomes using the various causes of death, we found the following mortality endpoints to demonstrate higher respective case-incidence rates as well as association with preLT diabetes: for deaths due to cardiac causes, those with pre-LT diabetes had higher incidence (11.33 per 1000 person-years, $95 \% \mathrm{Cl}$ 10.09-12.68 vs. 7.99 per 1000 person-years, 95\% $\mathrm{Cl} 7.11-8.94$ ) and higher risk ( $p=0.014$, aHR $1.2495 \% \mathrm{Cl} 1.04-1.46$ ); for deaths due to renal causes, those with diabetes had higher incidence (3.55 per 1000 person-years, $95 \%$ Cl 2.87-4.34 vs. 2.28 per 1000 person-years, 95\% Cl 1.83-2.82) and higher risk ( $\mathrm{p}=0.039$, aHR $1.3895 \% \mathrm{Cl} 1.02-1.87)$. Interestingly, those with diabetes had lower incidence ( 0.49 per 1000 person-years, $95 \% \mathrm{Cl} 0.26-0.84$ vs. 1.11 per 1000 person-years $95 \% \mathrm{Cl} 0.80-1.51$ ) and risk ( $p=0.010$, aHR $0.4295 \% \mathrm{Cl} 0.21-0.81$ ) of death due to graft rejection.

\section{Competing risk regression}

Additional analyses using the Fine-Gray sub-distribution hazard model with competing risks are demonstrated in Supplementary Table 1. These models used either all-cause mortality or graft failure as the primary endpoint, while setting the alternative outcome as a competing risk, thus accounting for the sub-distribution probability of developing the competing risk in the models. Using iterations of regression analyses, the final model with recipient and donor covariates showed the presence of pre-LT diabetes to be associated with all-cause mortality ( $p<0.001$, aHR $1.2395 \% \mathrm{Cl} 1.14-1.32)$. However, there was no association between pre-LT diabetes and graft failure ( $p=0.550$, aHR $1.0695 \% \mathrm{Cl}$ 0.89-1.26).

\section{Discussion}

The results of the study show that the presence of pre-LT diabetes is associated with increased recipient all-cause mortality as well as deaths due to cardiac and renal causes. Prior single-center and institutional studies also corroborate the current findings and demonstrate that recipients with diabetes develop a higher risk for adverse all-cause mortality and other immediate and subacute post-LT complications (27, 28). However, we expand upon prior studies by including additional organ-specific causes of death as endpoints and evaluating them using the successive Cox iteration analysis, which controls for both recipient and donor covariates in order to enhance the precision of the statistical outputs.

The relationship between diabetes and adverse post-LT outcomes in NASH patients may be explained by the different mechanisms by which diabetes affects recovery (29-32). For instance, it is known from surgical literature that diabetes affects the microvasculature and reduces perfusion of capillaries around the surgical sites (33-35), leading to a delayed wound healing response that potentiates post-operational wound complications $(36,37)$. Furthermore, pre-LT diabetes is known to generate atherosclerotic changes in the coronaries (38), which make patients susceptible to cardiac events due to low perfusion states and 
hypotension $(39,40)$. This phenomenon is consistent with the finding in the current study that those with pre-LT diabetes suffered higher incidence rates of deaths due to cardiac causes $(41,42)$. Furthermore, the chronic progression of diabetes affects the renal system by damaging the capillary layers of renal glomeruli $(43,44)$, which in effect will disrupt the renal hemodynamics and cause ischemic damage (45). This is in agreement with the baseline pre-LT data that showed that diabetic recipients had higher levels of creatinine, which presupposes that microvascular damage had likely already occurred $(46,47)$. These specific causes of death contributed to the overall mortality, in addition to the disruptive effects of diabetes on surgical recovery mechanisms. Interestingly, recipient diabetes had minimal effects on the graft itself, and paradoxically, those with diabetes had lower rates of death due to graft rejection. While further studies are needed, we can postulate that the presence of diabetes in the recipient confers an immunosuppressive effect on host immunity $(48,49)$ that prospectively delays or mitigates the immune response following LT. Prior studies have largely elucidated the various mechanisms of diabetes and how it affected the immune system $(50,51)$, which included diminishing the phagocytic activities of macrophages, inhibiting the normal transition and chemotaxis of immune cells, disrupting the intercellular signaling cascades, as well as suboptimizing the pathogen recognition and binding (52). It is likely that these immunologic manifestations of diabetes reduced the mortality risks that are associated with graft complications, as it was observed in the current study.

In conclusion, the presence of pre-LT diabetes is a risk factor for adverse post-LT outcomes, including allcause mortality and deaths due to cardiac and renal causes. Glven the current finding, this warrants screening of NASH candidates who are pending LT for diabetes. After diagnosing and classifying the severity of diabetes, preoperative strategies should be implemented to attenuate the metabolic risks (5355). Such measures may include multidisciplinary efforts with the endocrinology team in tirating antidiabetic medications and providing insulin therapy to reduce insulin resistance and improve metabolic parameters. In addition, further investigative efforts should be made to screen these patients of their cardiac and renal statuses prior to LT, so that cardiac or renal disorders can be amended using appropriate interventional treatments (56-59). Following LT, patients should follow up longitudinally with surgical and endocrine specialists for proper titration of antidiabetic medications and screening for postLT complications $(60,61)$.

\section{Limitations}

The limitation of this study involves the lack of severity data regarding the recipient diabetes risk $(53,62)$, as this data was not available in the original database. Thus, further prospective studies are needed to stratify the risks using the diabetes-related parameters and to prognosticate the outcomes using each stratified category. Otherwise, given that the study was performed retrospectively, there are study-inherent biases in the selection procedure that may bias the outcomes. However, the inclusion/exclusion criteria applied to selecting the patients was comprehensive and globally applied to the NASH population, thus minimizing the risks of selection bias. Furthermore, given the limitation in the definitions, the populations dating back to early 2000 s included those with cryptogenic cirrhosis/liver disease, which may have introduced a degree of heterogeneity in the selected population.

Page $7 / 20$ 


\section{Conclusion}

The presence of pre-LT diabetes is associated with increased deaths and higher incidence rates in allcause mortality, cardiovascular and renal causes after LT.

\section{Declarations}

Data Availability: Scientific data used in the study is available upon reasonable request to the corresponding author.

Animal Research (Ethics): This study did not involve animals.

Consent to Participate (Ethics): As this study used a publicly available registry, there was no consent procedure required in the study as no candidates were enrolled.

Consent to Publish (Ethics): On behalf of the authors, I, the corresponding author, give consent to the publishers to publish the manuscript as a journal article.

Plant Reproducibility: The methodologies contained and delineated in the manuscript outlines the study design and the data collection methods implemented in the paper, in order that the reproducibility of the paper can be optimized.

Clinical Trials Registration: This paper did not involve a clinical trial.

\section{Author Contribution:}

David Uihwan Lee MD

Roles: Conceptualization, data curation, formal analysis, investigation, methodology, supervision, validation, writing - original draft, writing - review \& editing

John Han

Roles: methodology, writing - original draft, visualization, writing - review \& editing

Ki Jung Lee

Roles: writing - original draft, investigation

Jean Kwon

Roles: writing - original draft, investigation

Gregory Hongyuan Fan

Roles: writing - original draft, investigation 
Nathalie Helen Urrunaga MD MS

Roles: Conceptualization, supervision, writing - review \& editing

Conflict of Interest: The authors of this manuscript certify they share no affiliation or involvement with any organization or entity with any financial interest or non-financial interest in the subject matter or materials discussed in this manuscript. None declared.

Funding: There was no funding provided.

\section{References}

1. Younossi ZM, Koenig AB, Abdelatif D, Fazel Y, Henry L, Wymer M. Global epidemiology of nonalcoholic fatty liver disease-Meta-analytic assessment of prevalence, incidence, and outcomes. Hepatology. 2016;64(1):73-84.

2. NCD Risk Factor Collaboration (NCD-RisC). Trends in adult body-mass index in 200 countries from 1975 to 2014: a pooled analysis of 1698 population-based measurement studies with $19 \cdot 2$ million participants. Lancet. 2016;387(10026):1377-1396.

3. Buzzetti E, Pinzani M, Tsochatzis EA. The multiple-hit pathogenesis of non-alcoholic fatty liver disease (NAFLD). Metabolism. 2016;65(8):1038-1048.

4. Khan RS, Bril F, Cusi K, Newsome PN. Modulation of Insulin Resistance in Nonalcoholic Fatty Liver Disease. Hepatology. 2019;70(2):711-724.

5. Marchesini G, Brizi M, Morselli-Labate AM, et al. Association of nonalcoholic fatty liver disease with insulin resistance. Am J Med. 1999;107(5):450-455.

6. Kumashiro N, Erion DM, Zhang D, et al. Cellular mechanism of insulin resistance in nonalcoholic fatty liver disease. Proc Natl Acad Sci U S A. 2011;108(39):16381-16385.

7. Titchenell PM, Quinn WJ, Lu M, et al. Direct Hepatocyte Insulin Signaling Is Required for Lipogenesis but Is Dispensable for the Suppression of Glucose Production. Cell Metab. 2016;23(6):1154-1166.

8. Wree A, Schlattjan M, Bechmann LP, et al. Adipocyte cell size, free fatty acids and apolipoproteins are associated with non-alcoholic liver injury progression in severely obese patients. Metabolism. 2014;63(12):1542-1552.

9. Ertle J, Dechêne A, Sowa JP, et al. Non-alcoholic fatty liver disease progresses to hepatocellular carcinoma in the absence of apparent cirrhosis. Int J Cancer. 2011;128(10):2436-2443.

10. Haflidadottir S, Jonasson JG, Norland H, et al. Long-term follow-up and liver-related death rate in patients with non-alcoholic and alcoholic related fatty liver disease. BMC Gastroenterol. 2014;14:166.

11. Wong RJ, Cheung R, Ahmed A. Nonalcoholic steatohepatitis is the most rapidly growing indication for liver transplantation in patients with hepatocellular carcinoma in the U.S. Hepatology. 2014;59(6):2188-2195. 
12. Feldstein AE, Charatcharoenwitthaya P, Treeprasertsuk S, Benson JT, Enders FB, Angulo P. The natural history of non-alcoholic fatty liver disease in children: a follow-up study for up to 20 years. Gut. 2009;58(11):1538-1544.

13. Wong RJ, Aguilar M, Cheung R, et al. Nonalcoholic steatohepatitis is the second leading etiology of liver disease among adults awaiting liver transplantation in the United States. Gastroenterology. 2015;148(3):547-555.

14. Merion RM, Schaubel DE, Dykstra DM, Freeman RB, Port FK, Wolfe RA. The survival benefit of liver transplantation. Am J Transplant. 2005;5(2):307-313.

15. Karvellas CJ, Lescot T, Goldberg P, et al. Liver transplantation in the critically ill: a multicenter Canadian retrospective cohort study. Crit Care. 2013;17(1):R28.

16. Tsai MS, Wang YC, Wang HH, Lee PH, Jeng LB, Kao CH. Pre-existing diabetes and risks of morbidity and mortality after liver transplantation: A nationwide database study in an Asian population. Eur $J$ Intern Med. 2015;26(6):433-438.

17. Hoehn RS, Singhal A, Wima K, et al. Effect of pretransplant diabetes on short-term outcomes after liver transplantation: a national cohort study. Liver Int. 2015;35(7):1902-1909.

18. Shields PL, Tang H, Neuberger JM, Gunson BK, McMaster P, Pirenne J. Poor outcome in patients with diabetes mellitus undergoing liver transplantation. Transplantation. 1999;68(4):530-535.

19. Dare AJ, Plank LD, Phillips ARJ, et al. Additive effect of pretransplant obesity, diabetes, and cardiovascular risk factors on outcomes after liver transplantation. Liver Transpl. 2014;20(3):281290.

20. Emerging Risk Factors Collaboration, Sarwar N, Gao P, et al. Diabetes mellitus, fasting blood glucose concentration, and risk of vascular disease: a collaborative meta-analysis of 102 prospective studies. Lancet. 2010;375(9733):2215-2222.

21. Anand SS, Dagenais GR, Mohan V, et al. Glucose levels are associated with cardiovascular disease and death in an international cohort of normal glycaemic and dysglycaemic men and women: the EpiDREAM cohort study. Eur J Prev Cardiol. 2012;19(4):755-764.

22. Nicholls SJ, Tuzcu EM, Kalidindi S, et al. Effect of diabetes on progression of coronary atherosclerosis and arterial remodeling: a pooled analysis of 5 intravascular ultrasound trials. $J$ Am Coll Cardiol. 2008;52(4):255-262.

23. Steggerda JA, Kim IK, Todo T, Malinoski D, Klein AS, Bloom MB. Liver Transplant Survival Index for Patients with Model for End-Stage Liver Disease Score $\geq 35$ : Modeling Risk and Adjusting Expectations in the Share 35 Era. J Am Coll Surg. 2019;228(4):437-450.e8.

24. Xing M, Kim HS. Independent prognostic factors for posttransplant survival in hepatocellular carcinoma patients undergoing liver transplantation. Cancer Med. 2017;6(1):26-35.

25. Austin PC, Steyerberg EW, Putter H. Fine-Gray subdistribution hazard models to simultaneously estimate the absolute risk of different event types: Cumulative total failure probability may exceed 1. Stat Med. 2021;40(19):4200-4212. 
26. Zhang Z. Multiple imputation with multivariate imputation by chained equation (MICE) package. Ann Trans/ Med. 2016;4(2):30.

27. Samuelson AL, Lee M, Kamal A, Keeffe EB, Ahmed A. Diabetes mellitus increases the risk of mortality following liver transplantation independent of MELD score. Dig Dis Sci. 2010;55(7):2089-2094.

28. Volk ML, Hernandez JC, Lok AS, Marrero JA. Modified Charlson comorbidity index for predicting survival after liver transplantation. Liver Transpl. 2007;13(11):1515-1520.

29. Xie H, Tsybenko VA, Johnson MV, Lautt WW. Insulin resistance of glucose response produced by hepatic denervations. Can J Physiol Pharmacol. 1993;71(2):175-178.

30. Latour MG, Lautt WW. The hepatic vagus nerve in the control of insulin sensitivity in the rat. Auton Neurosci. 2002;95(1-2):125-130.

31. Moore MC, Satake S, Baranowski B, Hsieh PS, Neal DW, Cherrington AD. Effect of hepatic denervation on peripheral insulin sensitivity in conscious dogs. Am J Physiol Endocrinol Metab. 2002;282(2):E286-E296.

32. Xie H, Lautt WW. Insulin resistance caused by hepatic cholinergic interruption and reversed by acetylcholine administration. Am J Physiol. 1996;271(3 Pt 1):E587-E592.

33. Pedrosa ME, Montero EF, Nigro AJ. Liver microcirculation after selective denervation. Microsurgery. 2001;21(4):163-165.

34. Vollmar B, Menger MD. The hepatic microcirculation: mechanistic contributions and therapeutic targets in liver injury and repair. Physiol Rev. 2009;89(4):1269-1339.

35. Uz Z, Ince C, Shen L, Ergin B, van Gulik TM. Real-time observation of microcirculatory leukocytes in patients undergoing major liver resection. Sci Rep. 2021;11(1):4563.

36. Palladino R, Tabak AG, Khunti K, et al. Association between pre-diabetes and microvascular and macrovascular disease in newly diagnosed type 2 diabetes. BMJ Open Diabetes Res Care. 2020;8(1).

37. Alfonso AR, Kantar RS, Ramly EP, et al. Diabetes is associated with an increased risk of wound complications and readmission in patients with surgically managed pressure ulcers. Wound Repair Regen. 2019;27(3):249-256.

38. Dokken BB. The Pathophysiology of Cardiovascular Disease and Diabetes: Beyond Blood Pressure and Lipids. Diabetes Spectr. 2008;21(3):160-165.

39. Muhlestein JB, Anderson JL, Horne BD, et al. Effect of fasting glucose levels on mortality rate in patients with and without diabetes mellitus and coronary artery disease undergoing percutaneous coronary intervention. Am Heart J. 2003;146(2):351-358.

40. Patel KL. Impact of tight glucose control on postoperative infection rates and wound healing in cardiac surgery patients. J Wound Ostomy Continence Nurs. 2008;35(4):397-404; quiz 405-406.

41. Roccaro GA, Goldberg DS, Hwang WT, et al. Sustained Posttransplantation Diabetes Is Associated With Long-Term Major Cardiovascular Events Following Liver Transplantation. Am J Transplant. 2018;18(1):207-215. 
42. Albeldawi M, Aggarwal A, Madhwal S, et al. Cumulative risk of cardiovascular events after orthotopic liver transplantation. Liver Transpl. 2012;18(3):370-375.

43. Alicic RZ, Rooney MT, Tuttle KR. Diabetic Kidney Disease: Challenges, Progress, and Possibilities. Clin J Am Soc Nephrol. 2017;12(12):2032-2045.

44. Toth-Manikowski S, Atta MG. Diabetic Kidney Disease: Pathophysiology and Therapeutic Targets. J Diabetes Res. 2015;2015:697010.

45. Pálsson R, Patel UD. Cardiovascular complications of diabetic kidney disease. Adv Chronic Kidney Dis. 2014;21(3):273-280.

46. Pandya D, Nagrajappa AK, Ravi KS. Assessment and Correlation of Urea and Creatinine Levels in Saliva and Serum of Patients with Chronic Kidney Disease, Diabetes and Hypertension- A Research Study. J Clin Diagn Res. 2016;10(10):ZC58-ZC62.

47. Campbell MS, Kotlyar DS, Brensinger CM, et al. Renal function after orthotopic liver transplantation is predicted by duration of pretransplantation creatinine elevation. Liver Transpl. 2005;11(9):10481055.

48. Liu FC, Lin HT, Lin JR, Yu HP. Impact of immunosuppressant therapy on new-onset diabetes in liver transplant recipients. Ther Clin Risk Manag. 2017;13:1043-1051.

49. Price CL, Hassi HOSA, English NR, Blakemore AIF, Stagg AJ, Knight SC. Methylglyoxal modulates immune responses: relevance to diabetes. J Cell Mol Med. 2010;14(6B):1806-1815.

50. Berbudi A, Rahmadika N, Tjahjadi Al, Ruslami R. Type 2 Diabetes and its Impact on the Immune System. Curr Diabetes Rev. 2020;16(5):442-449.

51. Johal S, Jackson-Spence F, Gillott H, et al. Pre-existing diabetes is a risk factor for increased rates of cellular rejection after kidney transplantation: an observational cohort study. Diabet Med. 2017;34(8):1067-1073.

52. Daryabor G, Atashzar MR, Kabelitz D, Meri S, Kalantar K. The Effects of Type 2 Diabetes Mellitus on Organ Metabolism and the Immune System. Front Immunol. 2020;11:1582.

53. Wallia A, Schmidt K, Oakes DJ, et al. Glycemic Control Reduces Infections in Post-Liver Transplant Patients: Results of a Prospective, Randomized Study. J Clin Endocrinol Metab. 2017;102(2):451459.

54. Keddis MT, El Ters M, Rodrigo E, et al. Enhanced posttransplant management of patients with diabetes improves patient outcomes. Kidney Int. 2014;86(3):610-618.

55. Lamos EM, Wijesinha MA, Ramhmdani S, Magder LS, Silver KD. Role of glycemic control on hospitalrelated outcomes in patients with diabetes mellitus undergoing renal transplantation. Diabetes Metab Syndr Obes. 2017;10:13-17.

56. Ye C, Saincher M, Tandon P, et al. Cardiac work-up protocol for liver transplant candidates: experience from a single liver transplant centre. Can J Gastroenterol. 2012;26(11):806-810.

57. Findlay JY, Keegan MT, Pellikka PP, Rosen CB, Plevak DJ. Preoperative dobutamine stress echocardiography, intraoperative events, and intraoperative myocardial injury in liver transplantation. 
Transplant Proc. 2005;37(5):2209-2213.

58. Zoghbi GJ, Patel AD, Ershadi RE, Heo J, Bynon JS, Iskandrian AE. Usefulness of preoperative stress perfusion imaging in predicting prognosis after liver transplantation. Am J Cardiol. 2003;92(9):10661071.

59. Andreoli MCC, Souza NKG de, Ammirati AL, et al. Predictors of renal function recovery among patients undergoing renal replacement therapy following orthotopic liver transplantation. PLoS One. 2017;12(6):e0178229.

60. Davidson JA, Wilkinson A, International Expert Panel on New-Onset Diabetes after Transplantation. New-Onset Diabetes After Transplantation 2003 International Consensus Guidelines: an endocrinologist's view. Diabetes Care. 2004;27(3):805-812.

61. Baldwin D Jr, Duffin KE. Rosiglitazone treatment of diabetes mellitus after solid organ transplantation. Transplantation. 2004;77(7):1009-1014.

62. Jin HY, Lee KA, Kim YJ, et al. The Degree of Hyperglycemia Excursion in Patients of Kidney Transplantation (KT) or Liver Transplantation (LT) Assessed by Continuous Glucose Monitoring (CGM): Pilot Study. J Diabetes Res. 2019;2019:1757182.

\section{Tables}

Table 1: Baseline Characteristics of Liver Transplant Recipients Stratified Using Recipients Diabetes 


\begin{tabular}{|c|c|c|c|c|c|c|c|}
\hline \multirow[b]{2}{*}{ Recipient Variables } & \multicolumn{3}{|c|}{ With Diabetes } & \multicolumn{4}{|c|}{ Without Diabetes } \\
\hline & $\begin{array}{l}n= \\
6324\end{array}$ & $\begin{array}{l}(43.39 \\
\%)\end{array}$ & SD & $\begin{array}{l}n= \\
8251\end{array}$ & $\begin{array}{l}(56.61 \\
\%)\end{array}$ & SD & $\begin{array}{l}\text { p- } \\
\text { value }\end{array}$ \\
\hline \multicolumn{8}{|l|}{ Demographics } \\
\hline Age (year) & 58.50 & & 8.31 & 54.50 & & 11.10 & $\begin{array}{l}< \\
0.001\end{array}$ \\
\hline Male (\%) & 58.10 & & & 56.90 & & & 0.170 \\
\hline Race & & & & & & & $<.001$ \\
\hline White (\%) & 77.90 & & & 78.60 & & & \\
\hline Black (\%) & 3.62 & & & 5.16 & & & \\
\hline Hispanic (\%) & 14.70 & & & 12.80 & & & \\
\hline Asian (\%) & 2.36 & & & 2.17 & & & \\
\hline Other (\%) & 1.44 & & & 1.31 & & & \\
\hline $\mathrm{BMI}\left(\mathrm{kg} / \mathrm{m}^{2}\right)$ & 31.10 & & 5.99 & 29.70 & & 6.39 & $\begin{array}{l}<.001 \\
0.001\end{array}$ \\
\hline \multicolumn{8}{|l|}{ Comorbidities } \\
\hline Hepatitis B (\%) & 4.06 & & & 5.47 & & & $\begin{array}{l}< \\
0.001\end{array}$ \\
\hline Hepatitis C (\%) & 14.50 & & & 15.00 & & & 0.430 \\
\hline $\begin{array}{l}\text { Alcoholic Liver Disease } \\
\text { (\%) }\end{array}$ & 27.00 & & & 33.90 & & & $\dot{0.001}$ \\
\hline Assistance $\ddagger$ & & & & & & & $<.001$ \\
\hline $0(\%)$ & 2.13 & & & 1.82 & & & \\
\hline $1(\%)$ & 14.00 & & & 15.60 & & & \\
\hline $2(\%)$ & 40.00 & & & 36.80 & & & \\
\hline $3(\%)$ & 43.90 & & & 45.70 & & & \\
\hline \multicolumn{8}{|l|}{ Hepatic Variables } \\
\hline Ascites & & & & & & & 0.750 \\
\hline Absent (\%) & 14.00 & & & 13.80 & & & \\
\hline Slight (\%) & 47.20 & & & 47.80 & & & \\
\hline Moderate (\%) & 38.80 & & & 38.30 & & & \\
\hline
\end{tabular}




\begin{tabular}{|c|c|c|c|c|c|}
\hline None (\%) & 24.50 & & 25.30 & & \\
\hline $1-2(\%)$ & 62.20 & & 61.20 & & \\
\hline 3-4 (\%) & 13.30 & & 13.50 & & \\
\hline TIPS Procedure (\%) & 14.20 & & 9.73 & & $<$ \\
\hline MELD Scores & 22.90 & 8.84 & 24.90 & 8.96 & $\begin{array}{l}< \\
0.001\end{array}$ \\
\hline \multicolumn{6}{|l|}{ Medications } \\
\hline $\begin{array}{l}\text { Mycophenolate } \\
\text { Mofetil (\%) }\end{array}$ & 82.00 & & 81.50 & & 0.460 \\
\hline Cyclosporine (\%) & 5.30 & & 4.79 & & 0.170 \\
\hline Tacrolimus (\%) & 90.00 & & 90.60 & & 0.200 \\
\hline Sirolimus (\%) & 2.02 & & 1.62 & & 0.082 \\
\hline Steroids (\%) & 90.70 & & 91.20 & & 0.370 \\
\hline \multicolumn{6}{|l|}{ Biomarkers } \\
\hline Albumin (mg/dL) & 3.07 & 0.71 & 3.03 & 0.73 & $\begin{array}{l}< \\
0.001\end{array}$ \\
\hline Creatinine (mg/dL) & 1.65 & 1.13 & 1.54 & 1.09 & $\begin{array}{l}< \\
0.001\end{array}$ \\
\hline INR & 1.93 & 0.86 & 2.18 & 1.21 & $\begin{array}{l}< \\
0.001\end{array}$ \\
\hline Total Bilirubin (mg/dL) & 8.30 & 10.50 & 10.90 & 11.30 & $<.001$ \\
\hline \multicolumn{6}{|l|}{ Donor Demographics } \\
\hline Age (years) & 44.20 & 17.30 & 42.80 & 16.90 & $\begin{array}{l}< \\
0.001\end{array}$ \\
\hline Male (\%) & 59.30 & & 58.90 & & 0.630 \\
\hline Race & & & & & 0.230 \\
\hline White (\%) & 65.40 & & 65.40 & & \\
\hline Black (\%) & 18.90 & & 18.50 & & \\
\hline Hispanic (\%) & 11.20 & & 12.00 & & \\
\hline Asian (\%) & 2.26 & & 2.33 & & \\
\hline
\end{tabular}




\begin{tabular}{|c|c|c|c|c|c|}
\hline Other (\%) & 2.18 & & 1.78 & & \\
\hline $\mathrm{BMI}\left(\mathrm{kg} / \mathrm{m}^{2}\right)$ & 28.30 & 6.88 & 28.00 & 6.56 & 0.037 \\
\hline \multicolumn{6}{|l|}{ Donor Biomarkers } \\
\hline Creatine $(\mathrm{mg} / \mathrm{dL})$ & 1.72 & 1.78 & 1.70 & 1.79 & 0.240 \\
\hline Total Bilirubin (mg/dL) & 0.91 & 0.94 & 0.90 & 0.86 & 0.770 \\
\hline
\end{tabular}

Table 2: Incidence Rates and Sequential Cox Regression Analysis Using Diabetes as a Prognostic Risk Factor for All-Cause Mortality, Graft Failure, and Specific Causes of Death 


\begin{tabular}{|c|c|c|c|c|c|c|c|}
\hline \multirow{2}{*}{\multicolumn{4}{|c|}{$\begin{array}{l}\text { (A) All-cause Mortality } \\
\text { Incidence Rates per } 1000 \text { Person-Years }\end{array}$}} & \multicolumn{4}{|c|}{ (B) Graft Failure } \\
\hline & & & & \multicolumn{4}{|c|}{ Incidence Rates per 1000 Person-Years } \\
\hline \multicolumn{2}{|c|}{ With Diabetes } & \multicolumn{2}{|c|}{$61.68(58.81-64.65)$} & \multicolumn{2}{|c|}{ With Diabetes } & \multicolumn{2}{|c|}{$9.52(8.38-10.76)$} \\
\hline \multicolumn{2}{|c|}{ Without Diabetes } & \multicolumn{2}{|c|}{$47.80(45.67-50.00)$} & \multicolumn{2}{|c|}{ Without Diabetes } & \multicolumn{2}{|c|}{$8.76(7.84-9.75)$} \\
\hline \multicolumn{4}{|c|}{ Sequential Cox Regressions } & \multicolumn{4}{|c|}{ Sequential Cox Regressions } \\
\hline Model & p-value & aHR & $95 \% \mathrm{Cl}$ & Model & p-value & aHR & $95 \% \mathrm{Cl}$ \\
\hline 1 & $<0.001$ & 1.20 & $(1.12-1.29)$ & 1 & 0.330 & 1.09 & $(0.92-1.29)$ \\
\hline 2 & $<0.001$ & 1.20 & $(1.12-1.28)$ & 2 & 0.457 & 1.07 & $(0.90-1.27)$ \\
\hline 3 & $<0.001$ & 1.19 & $(1.11-1.27)$ & 3 & 0.412 & 1.07 & $(0.90-1.28)$ \\
\hline tFM & $<0.001$ & 1.19 & $(1.11-1.27)$ & tFM & 0.306 & 1.10 & $(0.92-1.30)$ \\
\hline \multicolumn{4}{|c|}{ (C) Death due to General Cardiac Causes } & \multicolumn{4}{|c|}{ (D) Death due to Graft Rejection } \\
\hline \multicolumn{4}{|c|}{ Incidence Rates per 1000 Person-Years } & \multicolumn{4}{|c|}{ Incidence Rates per 1000 Person-Years } \\
\hline \multicolumn{2}{|c|}{ With Diabetes } & \multicolumn{2}{|c|}{$11.33(10.09-12.68)$} & \multicolumn{2}{|c|}{ With Diabetes } & \multicolumn{2}{|c|}{$0.49(0.26-0.84)$} \\
\hline \multicolumn{2}{|c|}{ Without Diabetes } & \multicolumn{2}{|c|}{$7.99(7.11-8.94)$} & \multicolumn{2}{|c|}{ Without Diabetes } & \multicolumn{2}{|c|}{$1.11(0.80-1.51)$} \\
\hline \multicolumn{4}{|c|}{ Sequential Cox Regressions } & \multicolumn{4}{|c|}{ Sequential Cox Regressions } \\
\hline Model & p-value & aHR & $95 \% \mathrm{Cl}$ & Model & p-value & aHR & $95 \% \mathrm{Cl}$ \\
\hline 1 & 0.023 & 1.21 & $(1.03-1.42)$ & 1 & 0.012 & 0.43 & $(0.22-0.83)$ \\
\hline 2 & 0.018 & 1.22 & $(1.03-1.44)$ & 2 & 0.011 & 0.42 & $(0.22-0.82)$ \\
\hline 3 & 0.019 & 1.22 & $(1.03-1.44)$ & 3 & 0.009 & 0.41 & $(0.21-0.80)$ \\
\hline tFM & 0.014 & 1.24 & $(1.04-1.46)$ & tFM & 0.010 & 0.42 & $(0.21-0.81)$ \\
\hline \multicolumn{8}{|c|}{ (E) Death due to General Renal Causes } \\
\hline \multicolumn{8}{|c|}{ Incidence Rates per 1000 Person-Years } \\
\hline \multicolumn{2}{|c|}{ With Diabetes } & \multicolumn{6}{|c|}{$3.55(2.87-4.34)$} \\
\hline \multicolumn{2}{|c|}{ Without Diabetes } & \multicolumn{2}{|c|}{$2.28(1.83-2.82)$} & & & & \\
\hline
\end{tabular}




\begin{tabular}{|c|c|c|c|}
\hline \multicolumn{4}{|c|}{ Sequential Cox Regressions } \\
\hline Model & p-value & aHR & $95 \% \mathrm{Cl}$ \\
\hline 1 & 0.024 & 1.41 & $(1.05-1.90)$ \\
\hline 2 & 0.026 & 1.41 & $(1.04-1.90)$ \\
\hline 3 & 0.044 & 1.37 & $(1.01-1.85)$ \\
\hline tFM & 0.039 & 1.38 & $(1.02-1.87)$ \\
\hline \multicolumn{4}{|c|}{ † FM indicates Final Model } \\
\hline \multicolumn{4}{|c|}{$\begin{array}{l}\text { Footnote: *Model } 1 \text { includes VOI (variable of interest) and demographics, model } 2 \text { includes VOI, } \\
\text { demographics, comorbidities, and medications, model } 3 \text { includes VOI, demographics, comorbidities, } \\
\text { medications, and biomarkers, model } 4 \text { includes VOI, demographics, comorbidities, medications, } \\
\text { biomarkers, and donor information }\end{array}$} \\
\hline
\end{tabular}

\section{Figures}


Figure 1: Patient Selection

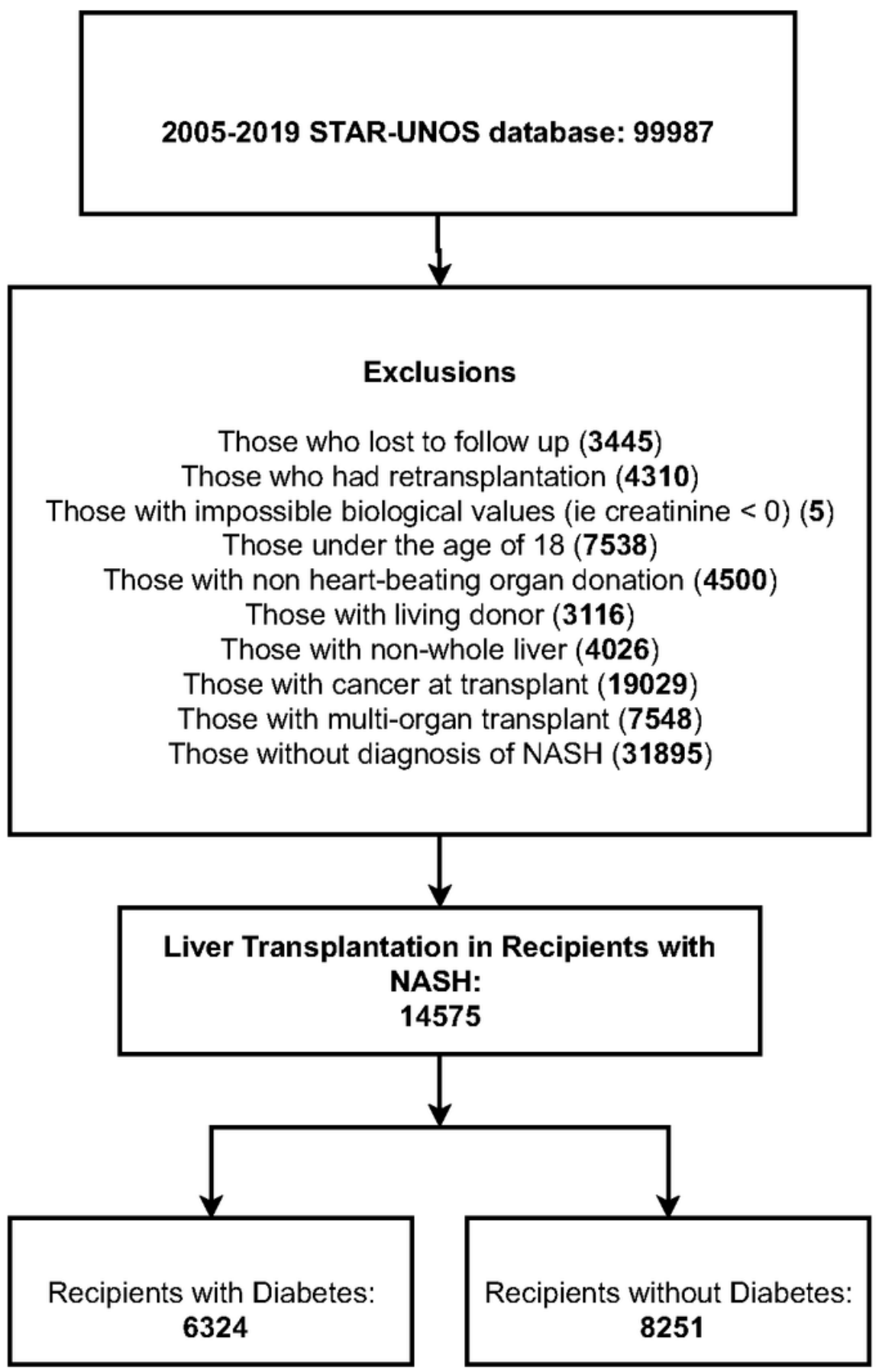

Figure 1

This figure represents the patient selection procedure for the study 
Figure 2: Prognostic Differences in the Cumulative Hazards of All-Cause Death and Graft Failure

\section{(A) All-Cause Mortality}

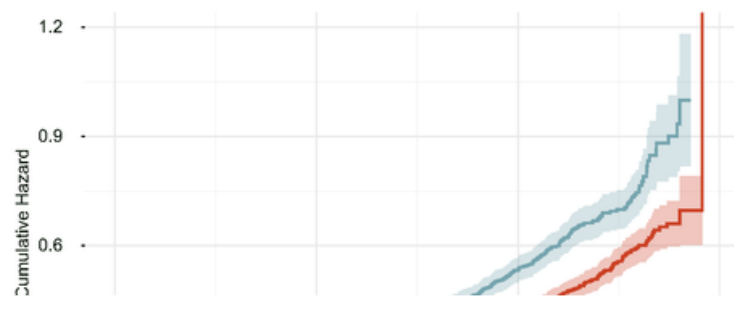

(B) Graft Failure

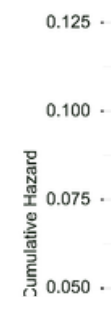

E Diabetes

$=$ No Diabetes

\section{Figure 2}

This figure represents the respective cumulative hazard curves comparing the presence or absence of preLT diabetes on all-cause mortality or graft failure as endpoints. The $x$-axis represents time in years and $y$ axis represents the cumulative hazard rates.

\section{Supplementary Files}

This is a list of supplementary files associated with this preprint. Click to download.

- SupplementaryFigure1.pdf

- SupplementaryFigure2.pdf

- SupplementaryTable1.docx 